\title{
Capital social e desenvolvimento local: nem cola, nem lubrificante social, mas campo eletromagnético*
}

\author{
Carlos R. S. Milani**
}

\begin{abstract}
Resumo
A literatura especializada acerca do capital social parte, de modo quase generalizado, da constatação empírica de que as variáveis econômicas não são suficientes para produzir modelos de desenvolvimento local que sejam socialmente justos e ambientalmente sustentáveis; reafirma, quase de forma consensual, que as redes de compromisso cívico, as normas de confiança mútua, os recursos advindos das redes sociais, a riqueza do tecido associativo e as instituições políticas têm impacto direto no incremento qualitativo da comunicação entre indivíduos e atores sociais, na produção de formas mais intensas de interação social e na redução dos dilemas da ação coletiva em torno das estratégias de desenvolvimento local. No entanto, um dos elementos críticos do debate sobre as relações entre capital social e desenvolvimento local diz respeito ao próprio conceito de desenvolvimento.
\end{abstract}

Palavras-chave: Desenvolvimento local. Capital social. Teoria social. Metáforas. Parâmetros metodológicos para pesquisa científica.

\begin{abstract}
In general terms, academic literature on social capital builds on the empirical evidence that economic variables are not sufficient to bring about local development models that are socially just and environmentally sustainable; it is almost consensual in reaffirming that civic engagement networks, norms of mutual trust, resources stemming from social networks, the wealth of associative tissues and political institutions do have a direct impact when it comes to a qualitative increase on the communication between individuals and social actors, the production of more intensive modalities of social interaction, and the reduction of collective action dilemmas around local development strategies. It goes without saying that one of the critical elements of the current debate on the relationships between social capital and local development concerns the local development concept itself.
\end{abstract}

Keywords: Local development. Social capital. Social theory. Metaphors. Methodological parameters for scientific research.

* Ponencia presentada al "X Colóquio Internacional sobre Poder Local" (11-12-13 de dezembro de 2006.

* Professor-adjunto do Departamento de Estudos Organizacionais e Professor do Núcleo de Pós-Graduação em Administração da Universidade Federal da Bahia (UFBA), Coordenador do Laboratório de Análise Política Mundial (LABMUNDO) e Pesquisador do CNPq. Concluiu em dezembro de 2005 o projeto de pesquisa intitulado Capital social, participação política e desenvolvimento local na Bahia, com financiamento da Fundação de Apoio à Pesquisa do Estado da Bahia (FAPESB). Atualmente, está desenvolvendo, com apoio do CNPq, o projeto de pesquisa sobre a temática Globalização e contestação política transnacional: organizações, redes e movimentos. (cmilani@ufba.br) 
Capital social e desenvolvimento local: nem cola, nem lubrificante social, mas campo eletromagnético - Carlos R. S. Milani

\section{Introdução: textos e contextos do desenvolvimento local}

Há inúmeras evidências empíricas e construções teóricas que, no campo acadêmico referente ao capital social (Atria, 2003; Baquero, 2002; Coleman, 1990; Durston, 2003; Ostrom e Ahn, 2003; Putnam, 1993; Woolcock, 1998), corroboram a seguinte hipótese: as redes de compromisso cívico, as normas de confiança mútua, os recursos advindos das redes sociais e a riqueza do tecido associativo influenciam diretamente o incremento qualitativo da comunicação entre indivíduos e atores sociais, a produção de formas mais intensas de interação social e a redução dos dilemas da ação coletiva em torno da definição de estratégias de desenvolvimento local. $\mathrm{O}$ dissenso entre os autores trabalhando sobre este tema encontra-se, porém, no nível ontológico que diz respeito ao próprio conceito de desenvolvimento.

De fato, é muito difícil discorrer sobre o desenvolvimento local sem integrar o seguinte paradoxo: o desenvolvimento é, ao mesmo tempo, um processo de transformação social e um projeto político-estratégico. Ou seja, ele é, concomitantemente, "análiseempiria" e "discurso-norma", podendo ser pensado sob a ótica analítica (os processos de desenvolvimento, suas causas, seus contextos variados, os constrangimentos estruturais e conjunturais, a centralidade da cultura em sua análise), mas também na perspectiva normativa e prescritiva de seus atores (o "como" do projeto, os valores que o embasam, os atores que sustentam tais valores, as representações sociais na construção dos problemas de desenvolvimento). Há, assim, uma constante tensão entre as visões analítica e normativa que podem ter os distintos atores do desenvolvimento, percebendo-o ora enquanto processo de transformação social de natureza emancipatória, ora enquanto estratégia viável de adaptação aos critérios dos mercados internacionais.

Tal paradoxo ganha ainda maior relevância no início dos anos 1990, quando o fim da Guerra Fria e a vitória anunciada 
da economia de mercados auto-regulados tornam mais opacas as distinções entre discursos e práticas do atores do desenvolvimento local. Essa "determinação global" ligada à evolução do capitalismo diz respeito às reformas institucionais do Estado, às relações entre as classes sociais, ao modo de operação daqueles que dominam a economia e a política, ao estilo das políticas públicas, à diluição das capacidades de intervenção social dos atores sociais, bem como à naturalização de uma ordem social individualista e possessiva (Comparato, 2001; Coutinho, 2001). Nesse contexto, há um deslocamento do conflito, ou talvez, há uma dimensão extraordinária do conflito que se soma às divisões clássicas entre os atores (que continuam empiricamente marcados pelas diferenças que podem, ainda em muitos contextos, separá-los). Esse deslocamento ou essa nova dimensão da conflitualidade corresponde a uma guerra das palavras e de seus sentidos no campo do desenvolvimento local. Afinal de contas, o que significa desenvolver? Que atores serão chamados a participar da definição dos "projetos de desenvolvimento local"? Nas experiências de desenvolvimento local, o que fazer da diferença entre os atores que não concordam com as normas vigentes do desenvolvimento? Qual seria a fronteira do "local" no processo de desenvolvimento? Perguntas aparentemente simples, mas cujas respostas remetem a clivagens profundas no abrangente contexto do desenvolvimento, concomitantemente campo de análise e campo estratégico de ação.

É assim que, no bojo dos processos de globalização econômica e financeira, o desenvolvimento local tende a ser considerado por muitos como a "resposta mágica" ou a única resposta possível às crises do desenvolvimento em geral. Ou seja, mesmo em países com alto grau de desigualdade estrutural como o Brasil, a "solução" para os problemas de acesso à educação, saúde, emprego ou renda adviria, na ótica de muitas agências de fomento e organizações internacionais de cooperação, da implementação de estratégias inovadoras de desenvolvimento local. O problema 
Capital social e desenvolvimento local: nem cola, nem lubrificante social, mas campo eletromagnético - Carlos R. S. Milani

está na exclusividade e na importância do foco no local-comunitário em tempos de aceleração da desordem global. Pois desenvolvimento local é, dessa forma, politicamente reinvestido e socialmente redefinido, sofrendo profunda alteração semântica. Ele passa a ser visto, por muitos analistas, como simples estratégia de adaptação e não mais de transformação social. Isso significa que o desenvolvimento local perde gradativamente o seu caráter político-conflitivo: os atores do desenvolvimento local devem produzir consensos mínimos quanto a prioridades e definir estratégias de "inserção pró-ativa" na economia global. Discussões sobre distribuição, reconhecimento e representação devem ser, preferencialmente, evitadas na produção desses consensos. Além disso, nesse diálogo entre os níveis local e global do desenvolvimento, perde-se um elo da regulação das solidariedades e esquece-se freqüentemente um ator político tradicionalmente chamado a arbitrar em matéria de desigualdades e injustiças. Este elo e este ator já foram considerados centrais inclusive para se pensarem as políticas de desenvolvimento local: trata-se evidentemente do nível nacional de regulação e das políticas públicas implementadas pelo Estado.

Conceber o desenvolvimento local no bojo dessas contradições potencializadas pelos processos de globalização comporta, assim, cuidados analíticos importantes. O primeiro deles referese à necessidade de não mais incorrer no risco do localismo que aprisiona atores, processos e dinâmicas de modo exclusivo ao seu lócus e a sua geografia mais próxima, sem fazer as necessárias conexões com outras escalas de poder e conflitos. O segundo risco seria o de conceber o desenvolvimento local de forma autônoma e independente de estratégias de desenvolvimento nacional e internacional, ou seja, imaginar que as estratégias locais de desenvolvimento econômico não tenham relação de interdependência, por exemplo, com políticas nacionais de ciência e tecnologia, ou com as negociações mundiais sobre a liberalização do comércio. Um terceiro risco concerne à multiplicação de estratégias e à falta de coerência entre as inúmeras iniciativas de desenvolvimento 
local, fazendo com que alguns territórios logrem a inserção dinâmica na globalização e outros permaneçam excluídos dos ganhos desse processo (Becker, 2002).

Por conseguinte, a compreensão das relações entre capital social e desenvolvimento local parte, no presente trabalho, de uma definição própria e de um olhar particular sobre os processos de desenvolvimento. O desenvolvimento local é aqui definido como um projeto político de transformação social situado histórica e geograficamente, com tempos e espaços específicos, sendo sempre e necessariamente consciente, coletivo e inclusivo. Com base nessa definição, este artigo divide-se em dois eixos principais: (1) análise das disputas conceituais que imperam no âmbito acadêmico em torno da definição do capital social; (2) apresentação do argumento de que as metáforas do capital social podem ajudar a melhor entendê-lo nos contextos múltiplos de desenvolvimento local. Em guisa de conclusão, a partir da experiência de pesquisa desenvolvida pelo autor do artigo entre 2003 e 2005 no Município de Pintadas na Bahia ${ }^{1}$, apresentam-se parâmetros teórico-metodológicos a fim de analisar as relações entre recursos produzidos no âmbito das redes sociais (capital social) e processos de transformação social (desenvolvimento).

O capital social no desenvolvimento local: de um conceito em disputa ...

Sabe-se que não há um único sentido dado ao capital social. Os diferentes conceitos procuram abranger algo que é produzido, acumulado e reproduzido no âmbito das relações sociais e que teria impacto na forma como funcionam as instituições ou evoluem os processos sociais (um deles sendo o desenvolvimento local). Não há, portanto, consenso quanto ao conceito de capital social. A sua definição segue sendo um terreno de disputas, sobretudo porque se tenta, concomitantemente, compatibilizar a

1 Para informações detalhadas do projeto de pesquisa, apoiado pela FAPESB (Bahia), sugere-se a consulta da página www.adm.ufba.br/capitalsocial. 
Capital social e desenvolvimento local: nem cola, nem lubrificante social, mas campo eletromagnético - Carlos R. S. Milani

lógica processual das relações sociais com o campo das políticas e estratégias de desenvolvimento local: capital social é fonte de recursos, é conjunto de normas, instituições e organizações, mas é também forma de reconsiderar o papel que normas e valores desempenham na vida econômica.

Lyda Judson Hanifan é considerado um dos pioneiros no uso do termo "capital social", definindo-o, em 1916, como o conjunto dos elementos tangíveis que mais contam na vida quotidiana das pessoas, tais como a boa vontade, a camaradagem, a simpatia, as relações sociais entre indivíduos e a família. O autor parte da idéia de que as redes sociais podem ter valor econômico ${ }^{2}$. Estudando o desenvolvimento rural comunitário nos EUA (no caso particular de Hundred no estado de West Virginia), Hanifan usa o termo capital em sentido figurado: o epicentro do capital social estaria na escola. Adotando uma visão pedagógica e partindo de autores como J. Dewey ("The School and Society") e W. Wilson ("Evolution of the Country Community"), Hanifan busca entender como valorizar a escola como centro norteador de relações sociais em uma comunidade. Porque o indivíduo não pode sobreviver sem a sociedade, o capital social é acumulado no sistema social a fim de produzir benefícios econômicos; tal acumulação se dá nos momentos de troca, durante os picnics e os encontros comunitários. No entanto, na concepção de Hanifan, o papel da liderança é central no processo de construção e fomento do capital social, seja por meio do crescimento do orgulho ou do sentimento de pertencimento à comunidade (Hanifan, 2003).

A partir dos anos 1960, Jane Jacobs, Glenn Loury, Pierre Bourdieu e Ekkehart Schlicht reutilizam o termo e teorizam sobre a noção de capital social (Meda, 2002). Segundo Robert Putnam, a urbanista Jane Jacobs teria sido a primeira analista social a utilizar, em 1961, o termo "capital social" com o seu significado atual

2 O texto original de Lyda Hanifan foi publicado em 1916 com a seguinte referência: HANIFAN, Lyda Johnson. The rural school community center. In: Annals of the American Academy of Political and Social Science, n. 67, 1916, pp. 130-138. 
(Putnam, 1995). Ela utiliza o termo capital social uma só vez, mas seu estudo trata dos valores imateriais e sociais nas lógicas de planejamento urbano: as conexões entre as pessoas produzem a coesão das comunidades urbanas, constituindo-se em redes de proteção do bairro contra estranhos (redes de confiança e de controle social). Para Jacobs, as comunidades urbanas são aqueles indivíduos que têm algo em comum, que compartilham valores e objetivos comuns. No entanto, como Hanifan, também lembra a importância da liderança (as famosas Mrs. Roosevelts nos bairros americanos) para dinamizar essas redes - que constituem o capital social das cidades: “(...) these networks are a city's irreplaceable social capital. Whenever the capital is lost, from whatever cause, the income from it disappears, never to return until and unless new capital is slowly and chancily accumulated" (Jacobs, 1961, p. 138) $)^{3}$.

Para James Coleman, o capital social é definido pela sua função, correspondendo a uma variedade de entidades (sistemas de apoio familiar, sistemas escolares, relações de trabalho) que têm duas características em comum: elas são uma forma de estrutura social e facilitam algumas ações dos indivíduos que se encontram dentro desta estrutura social. Seguindo um paradigma de análise fundado na teoria da escolha racional, Coleman considera que o capital social se consubstancia nas relações entre indivíduos (Coleman, 1990). É importante salientar que Coleman desenvolveu sua teoria do capital social como resultado de uma colaboração intelectual com o economista Gary Becker, de acordo

3 Jacobs parte do princípio de que nos EUA, nos anos 1960, trata-se muito mal da questão dos bairros urbanos (os chamados city neighborhoods). Este conceito de "bairro" é freqüentemente manipulado sentimentalmente, perdendo o planejador o bom senso necessário. Pensa-se o "bairro" como uma entidade fechada em si, para dentro, uniforme em contextos diferentes. O "bairro" para ela deve ser visto com um órgão de auto-gestão. Um aspecto importante de seu pensamento: Jacobs chama a atenção para a centralidade do humano e do social no planejamento urbano. "Statistical people are a fiction for many reasons, one of which is that they are treated as if infinitely interchangeable. Real people are unique, they invest years of their lives in significant relationships with other unique people, and are not interchangeable in the least" (Jacobs, 1961, p. 136). 
Capital social e desenvolvimento local: nem cola, nem lubrificante social, mas campo eletromagnético - Carlos R. S. Milani

com o qual o capital social seria toda interação social de efeito contínuo, diferente de comportamentos individuais atomizados e realizada fora do mercado - ou seja, uma externalidade que corrige as imperfeições do mercado (Fine, 2001, pp. 16 e 41).

Para os autores da escola institucionalista, é necessário entender as relações entre a riqueza da sociedade civil e o processo de construção da democracia, questionando-se acerca do impacto do compromisso cívico das entidades da sociedade civil (associações, clubes, sindicatos) no desempenho das instituições no processo de construção da democracia liberal. O capital social refere-se aqui a aspectos da organização social, tais como redes, normas e confiança, que facilitam a coordenação e a cooperação para benefício mútuo da coletividade; ele pode ser auferido pela intensidade da vida associativa (associações horizontais), leitura da imprensa, número de votantes, membros de corais e clubes de futebol, confiança nas instituições públicas, relevância do voluntariado (Putnam, 1993). Para ele, em uma comunidade ou uma sociedade "abençoada" por estoques "significativos" de capital social, as redes sociais de compromisso cívico incitam a prática geral da reciprocidade e facilitam o surgimento da confiança mútua (Putnam, 1995, p. 67).

Outros ainda, como o sociólogo francês Pierre Bourdieu, procuram associar ao capital social o conjunto de benefícios individuais e de classe oriundos de relações pessoais e valores socialmente compartilhados. Lembra Bourdieu que o capital social seria um dos tipos de recursos de que dispõem os indivíduos e os grupos sociais, os outros sendo o capital econômico, o capital simbólico, o histórico e o cultural. O capital social é, neste caso, o conjunto de relações e redes de ajuda mútua que podem ser mobilizadas efetivamente para beneficiar o indivíduo ou sua classe social. O capital social é propriedade do indivíduo e de um grupo; é concomitantemente estoque e base de um processo de acumulação que permite a pessoas inicialmente bem dotadas e situadas de terem mais êxito na competição social. A idéia de 
capital social remete aos recursos resultantes da participação em redes de relações mais ou menos institucionalizadas. Entretanto, o capital social é considerado uma quase-propriedade do indivíduo, visto que propicia, acima de tudo, benefícios de ordem privada e individual (Bourdieu, 1980 e 1986). Na França, o capital social dos indivíduos poderia, nesse sentido, permitir-lhes o acesso à informação, a profissões, favores, benefícios institucionais, independentemente da norma republicana de igualdade entre os cidadãos. Bourdieu desenvolve o conceito de capital social em termos de estratégia de classe; o capital social tem, para ele, o caráter de instrumento (da mesma forma que o capital econômico ou o capital cultural) que utilizam atores racionais com vistas a manter ou reforçar seu estatuto e seu poder na sociedade $\mathrm{e}^{4}$.

Para Mark Granovetter, as ações econômicas dos agentes estão inseridas em redes de relações sociais (a sua noção de embeddedness). As redes sociais são potencialmente criadoras de capital social, podendo contribuir na redução de comportamentos oportunistas e na promoção da confiança mútua entre os agentes econômicos. A duração das relações (consideradas positivas e simétricas), a intimidade criada no âmbito das redes, a intensidade emocional, os serviços recíprocos prestados são fatores essenciais para considerar a formação de laços fortes - base do capital social. Granovetter critica as duas visões do comportamento econômico: a visão neoclássica, que ele qualifica de sub-socializada, visto que percebe apenas os indivíduos de forma atomizada, desconectado das relações sociais; e a estruturalista e marxista, que ele qualifica de super-socializada, porquanto os indivíduos são considerados

4 Bourdieu dá ênfase aos processos de criação, diferenciação e manutenção de redes de relações duráveis como meios para concentrar o poder. Os grupos sociais são vistos como dispositivos de poder. Ele percebe o caráter duplo, bem como a natureza material e simbólica das relações de identidade em grupo. O artigo de Bourdieu é precursor e não se baseia em trabalhos anteriores; ele se interessa, principalmente, pelo capital social dos grupos sociais dominantes para fortalecer a sua dominação, garantir a sua reprodução e permitir a apropriação do capital social coletivo. Deste ponto de vista, ele afirma que a solidariedade é conseqüência dos lucros individuais que podem resultar do fato de pertencer de forma durável a um grupo. 
Capital social e desenvolvimento local: nem cola, nem lubrificante social, mas campo eletromagnético - Carlos R. S. Milani

em dependência total de seus grupos sociais e do sistema social a que pertencem (Granovetter, 1973; Granovetter, 1984).

Sciarrone (2000) traz uma contribuição particular aos estudos sobre capital social. Seu ensaio teórico é uma tentativa de aplicar o enfoque baseado no capital social sobre os estudos sociológi$\cos$ das redes mafiosas. Afirma que o capital social dos mafiosos permite entender como eles conseguem estabilizar e manter as relações de cooperação e de intercâmbio inclusive com agentes exteriores à organização-rede. É o que ele chama de "patrimônio relacional" que distingue a máfia das outras organizações criminais. Na máfia, o objetivo do poder (controle do território) tem prioridade sobre a acumulação de riquezas. Nesse sentido, a rede de relações representa um verdadeiro "capital" para os integrantes da máfia, considerada um sistema de regras que cria obrigações (importância simbólica e efetiva do segredo) e oportunidades para os diversos participantes que podem ter interesses não só heterogêneos, mas também conflitivos. Utilizando algumas categorias de Granovetter (1973), Sciarrone considera que os laços fortes (familiais) garantem maior estabilidade à máfia, mas são os laços fracos que permitem estender e dinamizar a rede. Com o seu capital social, os mafiosos podem obter o consenso necessário à sua sobrevivência e reprodução. Sem cair na armadilha da normatividade relacionada ao "bom capital social", Sciarrone lembra, no entanto, que o capital social das máfias destrói o capital social coletivo necessário à modernização e à produção dos bens públicos. Além disso, ele é produzido em detrimento dos que não fazem parte da organização ou que se recusam colaborar (rede fechada).

Atria (2003) busca entender o enfoque do capital social no contexto da América Latina, donde sua relevância particular para pensar o caso brasileiro. $\mathrm{O}$ autor propõe duas dimensões para $\mathrm{o}$ entendimento do conceito: o capital social entendido como uma capacidade específica de mobilização (liderança e empoderamento) de determinados recursos (relações de confiança, reciprocida- 
de e cooperação) por parte de um grupo; o capital social como disponibilidade de redes de relações sociais (associatividade horizontal ou vertical). Ele afirma que o capital social de um grupo social é a capacidade efetiva de mobilizar, produtivamente e em benefício do conjunto, os recursos associativos. O autor correlaciona a distribuição dos recursos associativos (disponibilidade de redes a que têm acesso os membros dos grupos) à distribuição da capacidade de mobilização dos grupos. Esta correlação ajudaria a explicar a pobreza e elaborar políticas públicas de combate contra a pobreza na América Latina, afirma Raúl Atria: "a disponibilidade de capital social nos grupos mais pobres é variável quando se leva em conta a capacidade de mobilização destes grupos, ou sua dotação de grupos associativos" (sic). O autor concebe capital social como sendo um dispositivo acionável pelo indivíduo em momentos de necessidade (capital social individual) ou como sendo o entrecruzamento de relações individuas (capital social coletivo).

Ostrom e Ahn (2003) salientam a explosão do interesse pelo tema (utilizando como indicadores o número de artigos publicados na base de dados Web of Science) a fim de explicar o desenvolvimento econômico e a ordem social e política. Lembram que a primeira geração de escritos sobre ação coletiva pressupunha indivíduos egoístas, atomizados e completamente racionais (dotados de racionalidade ilimitada); nesta geração de autores (por exemplo, Olson e Hardin usando o modelo do dilema do prisioneiro), o capital social tinha pouco poder explicativo sobre a ação coletiva. O capital social contaria mais para os autores de uma segunda geração da teoria da ação coletiva (influenciados por modelos comportamentais e pela teoria dos jogos). Nesta segunda geração (à qual pertence a própria Elinor Ostrom), preferências individuais heterogêneas são levadas em consideração. Por exemplo, além de aceitar que o comportamento dos indivíduos pode ser estimulado, a segunda geração de autores sobre ação coletiva acredita que existam indivíduos com genuína confiabilidade. Para Ostrom e Ahn, o capital social está no centro das difi- 
Capital social e desenvolvimento local: nem cola, nem lubrificante social, mas campo eletromagnético - Carlos R. S. Milani

culdades das ações coletivas contemporâneas, as quais - por sua vez - são a essência dos problemas econômicos e políticos atuais. Trata-se de capital porque se refere a um conjunto de recursos que produz benefícios para alguns indivíduos por algum tempo; o grupo de indivíduos pode ser pequeno (uma família, por exemplo); o benefício de alguns pode produzir-se em detrimento de outros. Haveria, segundo os autores, três formas principais de capital social que devem ser levados em conta no estudo da ação coletiva: confiabilidade (trustworthiness); redes; regras formais e informais (instituições). O capital social seria, assim, um atributo dos indivíduos e de suas relações que lhes permite aumentar a capacidade de solução de problemas de ação coletiva. Sugerem o seguinte esquema interpretativo do capital social:

Capital social $=$ confiabilidade + redes + instituições (enquanto fatores relacionados de modo complexo e não linear). Tais fatores geram confiança que, de acordo com variáveis contextuais, produz ações coletivas.

Ostrom e Ahn (2003) inserem o seu conceito de capital social na teoria mais ampla da ação coletiva. A confiança é a ligação central entre capital social e ação coletiva. A confiança é promovida quando indivíduos são confiáveis, quando eles se encontram em redes múltiplas (networked) e quando há instituições (regras formais e informais) que facilitem o crescimento da confiança. Diferentemente de Putnam, não consideram a confiança como uma forma de capital social, mas sim um resultado (um produto) de formas de capital social. A confiança é a ligação central entre capital social e ação coletiva; ela integra a previsibilidade de comportamentos dos agentes e, por isso, envolve a avaliação do risco de que um comportamento não seja efetivamente seguido. A confiança põe em relação as três formas de capital social citadas acima. A confiabilidade resulta de características particulares daqueles em quem confiamos (os valores intrínsecos dos indivíduos são também elementos essenciais para se saber se um indivíduo coopera ou não); no entanto, além da motivação individual, tam- 
bém devem ser levadas em consideração estruturas sociais e regras (sanção, punição) que marcam o contexto em que se situa o indivíduo. A confiabilidade é fundamental porquanto constitui um elemento que incentiva a reciprocidade: um indivíduo que baliza o seu comportamento pela reciprocidade é um indivíduo confiável. As redes incentivam a cooperação, mas sobretudo ajudam a conformar normas de reciprocidade. As instituições (prescrições, regras) também incluem o estado de direito, a atmosfera democrática, um governo transparente e com objetivos claros; no entanto, deve-se pensar tanto na prática das regras quanto em seu aspecto formal (o que corresponderia à máxima vigente no Brasil "a lei pega?").

Feita essa breve descrição dos conceitos apresentados por alguns dos inúmeros estudiosos do tema, é necessário reconhecer, diante da heterogeneidade dos conteúdos, que as críticas ao conceito, como lembram Ostrom e Ahn (2003), são múltiplas. Os autores as organizam em torno de três aspectos. Em primeiro lugar, como investir em capital social? Por exemplo, quando alguém participa de alguma atividade, esta pessoa o faz enquanto investimento ou enquanto consumo, para divertir-se ou acrescentar algo a sua vida? Ao participar de uma atividade, toda pessoa pode influenciar na conformação das regras, mas pode construir uma reputação que lhe renderá algum dividendo no futuro? Como considerar o investimento de tempo (bem cada vez mais raro para o sujeito global) em relações sociais como produtor de benefícios sociais? Um segundo aspecto diz respeito à venda ou à transferência de capital social: aqui é necessário separar os aspectos individuais dos aspectos relacionais do capital social. A questão, porém, é: como distinguir a reputação de um ator do benefício daí decorrente que pode inclusive ser comercializado? Como pensar essa distinção no plano de um indivíduo, de uma organização e de uma coletividade mais ampla? Em terceiro lugar, como medir o capital social? Thorstein Veblen já afirmava em 1908 que bens intangíveis (boa vontade, boa reputação) são capi- 
Capital social e desenvolvimento local: nem cola, nem lubrificante social, mas campo eletromagnético - Carlos R. S. Milani

tais que podem gerar benefícios de longo prazo $^{5}$, mas é possível medi-los? Três caminhos são apontados por Ostrom e Ahn (2003) para a mensuração do capital social: no âmbito da ação coletiva (quanto um indivíduo ganha ou perde ao ser recíproco ou não), usando o indicador da confiança a partir de grandes surveys nacionais e internacionais (que dão tendências macro e não servem para analisar comportamentos individuais) e usando o indicador do associativismo de Putnam.

Em artigo anterior (Milani, 2004), apontamos cinco elementos que podem ajudar-nos a analisar criticamente algumas das construções teóricas do capital social: a tautologia e a circularidade que caracteriza muitos conceitos de capital social disponíveis para pesquisa empírica; a pouca importância dada por muitos autores ao contexto das relações sociais em que se engendram recursos de capital social; a não-consideração da particularidade desse recurso tanto na sua formação quanto na sua reprodução, além de suas formas de acumulação; a importância de considerar o capital social enquanto bem coletivo e propriedade de uma comunidade; e a tendência a normatizar o capital social (definir o "bom" capital social, seguindo a tradição etnocêntrica do conceito de cultura cívica, por exemplo).

Locke (2001) assinala três ordens de críticas importantes às análises racionalistas e sociológicas sobre o capital social (mormente aos trabalhos de Douglas North e Robert Putnam): afirma que são estáticas ao assumirem que padrões de associativismo e/ ou capital social são fixos no tempo e no espaço; são mecanicistas

5 No início do século XX, Thorstein Veblen reconhecia que as teorias da produção e da distribuição, em economia, tinham o indivíduo hedonista como ponto de partida, sem necessariamente reconhecer que nem o indivíduo, nem a família podem manterse isolados do sistema social em que vivem. A continuidade entre o indivíduo e a sociedade, entre a família e a sociedade, é de natureza imaterial e intangível. São os valores imateriais (o que ele chamou de "immaterial equipment") que permitem o desenvolvimento dos indivíduos e dos grupos. Esses valores imateriais constituem um estoque social, disponível a todos os indivíduos de uma coletividade. Ver VEBLEN, Thorstein. On the Nature of Capital. In: Quarterly Journal of Economics, vol. XXII, n. 4, agosto de 1908, pp. 517-542. 
ao tratarem os pré-requisitos da confiança (institucionais ou sociológicos) como variáveis homogêneas binárias (ou as sociedades possuem as "instituições certas" ou não, e isso em estoques suficientes); são majoritariamente pessimistas quanto às possibilidades de se criar confiança nos contextos em que as condições e pré-requisitos favoráveis ao capital social não estejam presentes (Locke, 2001, p. 256).

Reis (2003) aponta uma série de lacunas metodológicas e teóricas no estudo de Putnam sobre o capital social. Apresentado como elemento facilitador da cooperação voluntária e como fator decisivo para a instauração de círculos virtuosos de um bom desempenho institucional, o capital social não é definido com precisão por Putnam, permanecendo vago e ambíguo ao englobar simultaneamente tanto variáveis "estruturais" quanto "atitudinais". Um conceito "guarda-chuva", o capital social putnamiano é empiricamente pouco apto à operacionalização (Reis, 2003).

Ben Fine (ao lado de S. Durlauf, R. Solow e K. Arrow) é considerado uma das principais vozes críticas ao conceito de capital social (Fine, 2001). Tendo a denúncia da "colonização" das ciências sociais pela economia como pano de fundo, Fine considera a teoria do capital social metodologicamente reducionista (Fine, 2001, p. 11) visto que pressupõe, ao afirmar a existência de um "capital social", que alguma forma de capital não seja social (donde sua crítica de natureza epistemológica). Como chamar de capital determinadas condições (valores, confiança, normas de sociabilidade, etc.) que não necessária e exclusivamente dizem respeito ao capitalismo? Como separar o capital social de seu contexto e da história das relações sociais em uma dada coletividade? Por que adotar uma perspectiva linear (causa-efeito) na consideração dos efeitos produzidos por algumas características das relações sociais na economia ou na política, externalizando as variáveis relativas a poder, classe e conflito?

... à construção de metáforas: o capital social como campo eletromagnético 
Capital social e desenvolvimento local: nem cola, nem lubrificante social, mas campo eletromagnético - Carlos R. S. Milani

No caso de nossa pesquisa, a idéia de concepção de uma metáfora para compreender o capital social foi inicialmente alimentada por um diálogo que mantivemos com moradores de Pintadas (Bahia), cidade em que foi desenvolvido e implementado o nosso modelo de análise empírica. O relato a seguir é esclarecedor a esse respeito. Quando iniciamos o processo de pesquisa em Pintadas, uma das questões que levamos a campo foi a seguinte: que conhecimento tem a população em geral do Município acerca das redes associativas locais, particularmente da Rede Pintadas de Solidariedade, que tem atuação local marcante? A resposta da população fica evidenciada no quadro abaixo:

\begin{tabular}{|l|c|c|c|c|c|}
\hline Quadro 1 - CONHECIMENTO DA REDE PINTADAS & & \\
\hline $\begin{array}{l}\text { • Você já ouviu falar } \\
\text { da Rede Pintadas? }\end{array}$ & $\mathrm{n}$ & $\%$ & $\begin{array}{l}\bullet \text { Você sabe o que é a } \\
\text { Rede Pintadas? }\end{array}$ & $\mathrm{n}$ & $\%$ \\
\hline Sim & 234 & 57,1 & Não sabe & 148 & 62,8 \\
\hline Não & 172 & 42,9 & Sabe & 88 & 37,2 \\
\hline TOTAL & 406 & 100,0 & TOTAL & 234 & 100,0 \\
\hline $\begin{array}{l}\text { • Como você avalia o } \\
\text { trabalho da Rede? }\end{array}$ & $\mathrm{n}$ & $\%$ & $\begin{array}{l}\bullet \text { Você sabe se houve } \\
\text { alguma melhoria em } \\
\text { Pintadas que, para você, }\end{array}$ & $\mathrm{n}$ & $\%$ \\
\hline Muito bom & 21 & 9,0 & Não sabe & \\
\hline Bom & 86 & 36,8 & Sabe & 125 & 53,4 \\
\hline Regular & 20 & 8,5 & TOTAL & 109 & 46,6 \\
\hline Ruim & 04 & 1,7 & & 234 & 100,0 \\
\hline Péssimo & 00 & 0,0 & & & \\
\hline Não sabe & 103 & 44,0 & & & \\
\hline TOTAL & 234 & 100,0 & & & \\
\hline
\end{tabular}

Fonte: Pesquisa "Capital Social, Participação Política e Desenvolvimento Local: Atores da Sociedade Civil e Políticas de Desenvolvimento Local na Bahia".

Ainda que muitos (57,1\% dos entrevistados) afirmem conhecer a Rede, não foram capazes de defini-la ou de associar alguma melhoria operacional na cidade ao trabalho da Rede. Isso foi razão de questionamento e debate com as lideranças locais em 
Pintadas, visto que a esse desconhecimento formal corresponde, paradoxalmente, forte apoio político à Rede e suas associações inclusive no momento das eleições municipais, visto que a Rede pôde eleger prefeitos em três mandatos consecutivos, desde as eleições municipais de 1996. O que explicaria tal fenômeno?

Fundamentalmente, a idéia de criação de uma "rede" teve sua origem na sugestão e incentivo de um agente de cooperação da Alemanha que, na segunda metade dos anos 1990, passou por Pintadas, lá se instalou e muito contribuiu para a dinamização das associações locais: ele deu inclusive a sugestão de que as associações locais se organizassem em Rede, respondendo aos critérios mais contemporâneos, aceitos nacional e internacionalmente, de uma gestão organizacional estratégica. A idéia prosperou no meio associativo e garantiu à Rede Pintadas de Solidariedade, além disso, a obtenção de um prêmio nacional pela Fundação Getúlio Vargas (Gestão Pública e Cidadania). A Rede obteve, assim, projeção na mídia e no mundo acadêmico, tanto no plano regional quanto no âmbito nacional.

No entanto, a Rede era conhecida e reconhecida como Movimento Social pelas pequenas comunidades rurais de Pintadas, que correspondem à aproximadamente $60 \%$ do total da população municipal. Ademais, ao falarem às populações rurais da idéia de "rede", as lideranças locais nos relataram que o imaginário coletivo sempre tendeu a representá-la como uma rede para dormir e não como uma rede para pescar. A rede para pescar, naquele contexto próprio do semi-árido baiano, era mais conhecida e reconhecida como "tarrafa". Ou seja, a fim de garantir seu reconhecimento social e corresponder à metáfora da cooperação entre seus distintos nós, a Rede Pintadas de Solidariedade deveria ter sido chamada, desde o início, de Tarrafa Pintadas...

O que nos revela esse relato? Basicamente que uma má metáfora pode impedir a compreensão de mensagens cruciais inclusive entre atores do desenvolvimento que são política e culturalmente 
Capital social e desenvolvimento local: nem cola, nem lubrificante social, mas campo eletromagnético - Carlos R. S. Milani

bastante próximos. Essa pista nos foi revelada pela pesquisa empírica e, a partir disso, fomos às teorias do capital social, cujos autores, muitos deles diante do imbroglio conceitual evidenciado anteriormente, utilizam metáforas para explicar o sentido do capital social nas relações econômicas e sociais contemporâneas. Daí o desafio que nos lançamos nesta parte do artigo: diante da profusão de definições, tentaremos buscar entender por que pensar metaforicamante poderia ajudar-nos a melhor compreender as relações entre capital social e desenvolvimento local.

Antes de mais nada, deve-se entender que, no processo de construção de uma metáfora, faz-se a comparação entre entes diferentes, retendo somente os aspectos que se consideram próximos e semelhantes, sempre com o objetivo último de engendrar um novo significado. A metáfora é uma figura de sentido fundada em relações de equivalência ou de analogia entre duas idéias ou campos semânticos, em que um é suprimido a fim de criar uma representação de como pode ser visto ou imaginado o outro. Ela é uma ferramenta metodológica bastante utilizada no campo do desenvolvimento, com vistas a criar uma rede de novos sentidos para o desenvolvimento, desconstruindo o seu economicismo, dando ênfase ao seu caráter político, holístico e multidimensional. Para tanto, parte-se de conceitos abstratos e busca-se estabelecer conceitos concretos: é o caso do desenvolvimento baobá (que se refere à endogenia, ao longo prazo, à sustentabilidade dos processos) em contraposição ao desenvolvimento eucalipto (exogenia, produtividade de curto prazo, alto impacto) em países africanos. Também merece destaque o desenvolvimento holograma de Morin e Kern (1995) que equivale à metáfora do desenvolvimento em rede. Austruy (1992) trabalha com a metáfora do desenvolvimento enquanto economia das metamorfoses, dando ênfase à transformação, ao caráter sempre mutante e profundamente cultural do desenvolvimento.

Em se tratando de capital social, esse processo criativo de natureza evidentemente cognitiva pode ser particularmente útil 
na medida em que o debate teórico-conceitual ainda se encontra bastante permeado de ambigüidades e incertezas quanto à natureza e aos conteúdos do capital social. Pensar uma imagem relativa ao capital social pode ajudar a esclarecer as funções desse recurso social, buscando por meio de associações descobrir novos significados e insights metodológicos. A premissa básica, neste artigo, é de que, como lembra Morgan (1996) ao analisar metáforas no caso do estudo das organizações contemporâneas ${ }^{6}$, o uso de metáforas para compreender as teorias e as explicações acerca das relações entre o capital social e o desenvolvimento local pode ser mais que um mero artifício estilístico e retórico; a metáfora pode revelar modos de pensar e maneiras de ver que se inter-relacionam com a nossa compreensão do capital social. Leva-nos à discussão teórico-metodológica por caminhos da hermenêutica de um fenômeno eminentemente complexo, dinâmico e subordinado a variações contextuais, cuja conceituação, como vimos anteriormente, é marcada pelo dissenso, pela polissemia e, em muitos casos, pela contradição polêmica dos conteúdos.

Como lembram Robinson e Robinson (2002, p. 60), o capital social já foi descrito como uma cola que mantém as coletividades unidas (cola social), como lubrificante sociológico que ajuda a diminuir os atritos sociais em uma coletividade (colaborando, assim, na redução dos custos de transação) e como um condensador de fumaça. Robert Putnam, em "Bowling Alone", afirma que o capital social de contato ("bonding social capital") seria uma super bonder sociológica, ao passo que o capital social do tipo relacional ("bridging social capital") seria um WD-40 sociológi$\mathrm{CO}^{7}$. Relatórios do Banco Mundial lembram que o capital social não pode ser definido apenas como o somatório das instituições subjacentes à sociedade, pois ele também se refere à "cola" (sic) que as mantém unidas (apud Robinson e Robinson, 2002). Ainda

6 No campo das organizações, Gareth Morgan trabalha no livro Imagens da Organização as metáforas da organização enquanto máquina, organismo, cérebro, sistema político, prisão psíquica, entre outras. Ver MORGAN, op. cit., pp. 16 e ss.

7

WD-40 é uma conhecida marca de um óleo lubrificante nos Estados Unidos. 
Capital social e desenvolvimento local: nem cola, nem lubrificante social, mas campo eletromagnético - Carlos R. S. Milani

o mesmo Banco Mundial afirma que "há uma quantidade impressionante de fumaça sendo produzida pelo capital social, cuja grande promessa se encontra no fato de poder funcionar como um condensador de fumaça que transforma pelo menos parte dessa fumaça em matéria concreta" 8 .

Seguindo os ensinamentos de Robinson e Robinson (2002), discordamos dessas metáforas. Em primeiro lugar, a cola sociológica enfatiza a estabilidade, a manutenção de uma união estável de aspectos sociais, não permitindo, porém, uma concepção dinâmica do capital social, visto que, enquanto cola, ele restringiria o movimento, a interação e a dinâmica social. A imagem da cola remete-se a uma visão estática do capital social que poderia confundir-se com a de coesão social: a cola mantém duas superfícies unidas e, dependendo da sua natureza química, de forma perene e sem flexibilidade. Pensar no capital social como um elemento que ajuda a evitar a transformação social seria, pelo menos, contraditório com a nossa definição de desenvolvimento local (apresentada na introdução).

Além disso, a metáfora da cola não seria específica ao capital social: a religião, as atividades comunitárias, a cultura, a xenofobia também seriam colas sociológicas. Em segundo lugar, a metáfora do lubrificante sociológico conduziria à idéia de que o capital social pode ser considerado como um facilitador do movimento e da interação em coletividades, prevenindo ou impedindo as forças sociais da conservação e da manutenção do status quo. O capital social ajudaria na aceleração das interações ao propiciar uma redução do atrito social e criar uma película protetora em torno das relações sociais. Essa imagem do capital social tendo uma função dinamizadora do movimento pressupõe, no entanto, o contato direto entre duas superfícies. Tanto no caso da metáfora da cola quanto na do lubrificante social, a proximidade é uma condição do capital social. Em ambas as metáforas,

8 Afirmações encontradas no website do Banco Mundial, em World Bank Social Capital Initiative, Working paper número 11. 
o capital social é um elemento externo que deve ser aplicado às superfícies. Ambas as metáforas pressupõem que o capital social pode ser (deve ser, nas visões mais normativas) introduzido (ou imposto) no sistema social. Se entendermos que o capital social existe dentro e a partir das relações sociais em uma dada coletividade, essa hipótese de sua inexistência em algumas sociedades e comunidades deve, evidentemente, ser descartada.

Como já afirmamos em artigo recente (Milani, 2004), concebemos o capital social como o somatório de recursos inscritos nos modos de organização cultural e política da vida social de uma população. $\mathrm{O}$ «social» refere-se à associação, ou seja, o capital pertence a uma coletividade, a uma rede, a uma sociedade. O capital social é compartilhado, não prescinde de reconhecimento social e não pertence, como outras formas de capital, a indivíduos ou grupos atomizados. Os recursos por ele produzidos podem, estes sim, ser apropriados por indivíduos ou grupos particulares; porém, o capital social não se gasta com o uso, ao contrário o uso do capital social o faz crescer. Nesse sentido, a noção de capital social -talvez mais um campo conceitual e menos um conceito propriamente dito- indica que os sentidos são compartilhados no nível do grupo e da sociedade, mais além dos níveis do indivíduo. Isso não implica que todos aqueles compartilhando determinado recurso de capital social se relacionem enquanto amigos ou membros de uma grande família; significa, no entanto, que o capital social existe e cresce a partir de relações de confiança e cooperação e não de relações baseadas no antagonismo. Além disso, capital social é «capital» porque se acumula, pode produzir benefícios, tem estoques que são acumulados e que podem ser utilizados e mantidos para uso futuro (Milani, 2004).

Portanto, como Robinson e Robinson (2002, p. 63), preferimos adotar a metáfora do campo eletromagnético para compreender imageticamente as relações entre capital social e desenvolvimento local. David Robinson define o capital social enquanto um conjunto de recursos a que um indivíduo ou um grupo tem 
Capital social e desenvolvimento local: nem cola, nem lubrificante social, mas campo eletromagnético - Carlos R. S. Milani

acesso em função do fato de pertencer a uma rede de intercâmbio e relações mutuamente proveitosas (Robinson, 2002, p.3). Aspectos desta estrutura social, tais como relações, normas e confiança social, podem ajudar a desenvolver a coordenação de atividades e a cooperação em torno de projetos de benefício comum. Recursos aqui referem-se a fatores, tais como estatuto, atenção, conhecimento, bem como oportunidades para participar e comunicar; não se referem simplesmente a conexões que dão acesso a recursos físicos e a informação. O capital social refere-se, então, à capacidade e à habilidade dos cidadãos de conectar-se (no inglês, connectedness). Redes de relações propiciam o fluxo e o intercâmbio de informações; criam espaços nos quais a comunicação pode ter lugar, o que é uma função-chave para sistemas sociais ricos em capital social, uma vez que abrem acesso à informação e permitem que opiniões e conhecimentos sejam compartilhados. O sentimento de pertencer ao grupo (identidade de grupo) é fundamental na definição do capital social; passamos, assim, de uma identidade baseada no conhecimento (Cogito ergo sum) a outra fundada no sentimento de pertencimento (Cognatos ergo sum).

Dessas opções teóricas resulta a metáfora do campo eletromagnético, cujo efeito é de longo alcance, podendo ser de atração ou repulsão (que diminuem, ambas, com a distância). A metáfora do campo eletromagnético pressupõe a existência de ondas de relações sociais e não de contato, fixo ou dinâmico, entre superfícies, No campo eletromagnético, não há necessidade de contatos diretos ou de proximidade geográfica, uma vez que os efeitos produzidos dependem das relações (as ondas) e a influência, positiva ou negativa, pode ocorrer a partir de um elemento situado fisicamente distante do campo.

Outrossim, no campo de força eletromagnética, há energia potencial em todos os átomos, sob a forma de eletricidade estática. Os átomos devem ser instigados e provocados para produzirem energia real. Contrariamente às idéias de cola ou lubrificante sociológico (que são materiais), as ondas do campo de força são 
o resultado de inúmeros elementos químicos não perceptíveis, remetendo-nos ao conjunto de fatores altamente imateriais e dificilmente mensuráveis do capital social (confiança, compromisso, sentimento de pertencimento). O campo de força faz parte de um ambiente, é por ele influenciado e varia de acordo com ele, dependendo das correntes e das ondas acionadas. O capital social enquanto campo de força pode, assim, provocar turbulências, relações de cooperação e distintas modalidades de regulação, dependendo dos recursos alocados e das redes de relações sociais, das formas de governança do sistema social, bem como do modo de construção e legitimação do conhecimento social.

\section{Conclusão: uma proposta teórico-metodológica em debate}

A construção desta proposta teórico-metodológica com vistas a analisar as relações entre capital social e desenvolvimento local fundamenta-se em dois pressupostos principais. Em primeiro lugar, considera-se o capital social enquanto campo de relações sociais e abandona-se a idéia de simplesmente agregar preferências individuais que busca definir o capital social enquanto mero resultado da densidade de redes sociais formadas pelos membros de uma dada coletividade. Isso significa que se adota, aqui, uma perspectiva patrimonial abrangente do capital social, o que implica concebê-lo enquanto estado global de uma coletividade. Este primeiro pressuposto tem como ponto de partida um questionamento teórico levantado por Meda (2002): por que não pensar o capital social em termos de quanto uma dada sociedade pode propiciar a seus integrantes, o grau de liberdade dos seus membros, o estado das desigualdades, o estoque global de educação, das produções culturais e artísticas, o capital ecológico? Meda (2002) desafia-nos a ultrapassar a definição de capital social exclusivamente enquanto qualidade das redes sociais e das relações entre os indivíduos, considerando a sociedade, a nação e o país como um todo um coletivo que também possui um bem próprio. O capital social corresponderia, assim, ao que Meda 
Capital social e desenvolvimento local: nem cola, nem lubrificante social, mas campo eletromagnético - Carlos R. S. Milani

(2002) chama de «estado social da nação» (état social de la nation). A sociedade disporia de um certo número de bens e recursos, de uma certa quantidade de capitais, cuja progressão, melhora, acumulação e qualidade (ou, no sentido contrário, cuja redução e degradação) dão forma ao macro-contexto institucional do capital social.

Em segundo lugar, parte-se do pressuposto de que os recursos sociais auxiliam o ator a obter seus objetivos e de que as posições sociais de origem (classe, raça, gênero) facilitam o acesso aos recursos sociais e seu uso (Bourdieu, 1980 e 1986; Lin, 1995). O capital social é um recurso e não uma característica imutável da estrutura social, podendo estar presente em todas as estruturas sociais, já que não há algumas estruturas sociais com mais capital social do que outras; o que difere entre elas são os recursos disponíveis de capital social. Além disso, como sublinha Bourdieu (1980), não se pode a priori dar um valor ao capital social, pois os valores que qualificam o capital social como positivo ou negativo advêm do enunciado dos objetivos e dos posicionamentos dos próprios atores políticos e sociais. Tais valores não podem ser pré-estabelecidos à própria análise do capital social.

Isso equivale a admitir aqui a chamada "latência" do capital social (Bourdieu, 1980; Lin, 1995). A latência, para retomar a metáfora anteriormente anunciada, corresponderia à energia estática do campo de força eletromagnética. Ela permite ao estudioso das relações entre capital social e desenvolvimento local evitar uma visão etnocêntrica que conduziria à comparação e à classificação de distintas estruturas sociais, com base em valores predeterminados. Por exemplo, a pesquisa sobre o capital social e sua relevância no desenvolvimento local poderia incorrer na tentação de estabelecer-se um "padrão" de capital social e, por conseguinte, medir sua presença em diferentes territórios, comunidades e nações, criando-se um ranking de acordo com uma visão predeterminada do "bom" capital social. 
Não há, assim, um bom e um mal capital social que se defina normativamente. Como já se afirmou anteriormente, o capital social das redes mafiosas, por exemplo, permite entender como o desenvolvimento de relações de cooperação e de intercâmbio pode ser altamente positivo na perspectiva dos membros dessa rede, uma vez que há benefícios individuais e coletivos produzidos pelos ganhos privados e "investimentos sociais" (habitação, segurança privada, infra-estrutura) realizados pelos traficantes. No entanto, tais relações de cooperação podem ser consideradas como profundamente negativas em função dos efeitos produzidos à sociedade globalmente considerada (organização da criminalidade, economia subterrânea, efeitos sociais do tráfico de drogas ilícitas, etc.).

A final de contas, sendo um recurso, o capital social é uma forma de capital que produz efeitos, mas se distingue fundamentalmente desses efeitos. É necessário, em termos de definição, separar as fontes do capital social de seus efeitos, porquanto os recursos do capital social situam-se em pelo menos dois níveis: no nível individual (enquanto recursos mobilizados pelo sujeito) e no nível da estrutura social (enquanto reservatório de recursos acumulados pela coletividade). Daí deriva a importância, em termos metodológicos, de analisar (a) como se dão os modos de constituição do capital social, (b) como as redes sociais produzem recursos individuais e benefícios coletivos do ponto de vista econômico, financeiro, cultural e social, (c) como o capital social participa na conversão de diferentes modalidades de capital em capital econômico.

Isso implica proceder a uma análise das estruturas das redes sociais e, ao mesmo tempo, das relações que se desenvolvem a partir da participação em redes. Como lembra Granovetter (1973), se forem excluídos os "laços fortes" e as ações expressivas (ações voluntárias e relacionadas com a expressão de valores próprios e subjetivos de solidariedade) e se forem levados em conta tãosomente os "laços fracos" e a ação instrumental, a qualidade e a 
Capital social e desenvolvimento local: nem cola, nem lubrificante social, mas campo eletromagnético - Carlos R. S. Milani

quantidade de recursos disponíveis na estrutura social e em uma rede social - bem como as formas pelas quais as relações dentro desta rede produzem frutos (outras formas de capital) - são essenciais para pensar-se a conversão de capital social em capital econômico. Bourdieu (2002) reafirma que a transubstanciação ou a conversão de, por exemplo, capital simbólico em capital econômico é sempre arriscada, pois o nome, a imagem e a marca podem converter-se em capital econômico sob certas condições e dentro de certos limites, e mais particularmente sob certas condições temporais ${ }^{9}$.

Para que ocorra essa conversão, o capital social tem um papel essencial, pois ele atua por meio das relações de obrigações sociais e necessita do tempo para consolidar-se enquanto facilitador das possibilidades de transubstanciação. É somente com o tempo que se tende a conquistar a gratidão de outrem, a sua confiança, quiçá o seu reconhecimento. Todas as outras formas de capital (cultural, simbólico) têm o capital econômico na sua raiz, mas esta raiz somente é capaz de produzir capital econômico por meio de capital social. Em última instância, ao conceber o capital social enquanto recurso e vetor de conversão entre diferentes formas de capital, propõe-se ultrapassar a visão economicista (que tudo reduz ao econômico), mas também se busca ir além do semiologismo (estruturalismo, interacionismo simbólico, etno-

9 A duração do renome do costureiro, por exemplo, é fator central. Chanel, por exemplo, criou a religião do pequeno tailleur e Jeanne Lanvin converteu-se em um nome de prestígio. Uma parte da autoridade e do prestígio está aliada à tradição do nome («maison fondée en...»), mas também contam o capital de autoridade e o capital de relações. O costureiro é diretor de uma empresa de produção de bens simbólicos; ele dirige uma alquimia simbólica; seu ato da criação confere promoção ontológica ao bem criado. No entanto, há igualmente o carisma do costureiro (o responsável pela criação) e sua rede de relações. Por isso, toda teoria econômica da produção de bens simbólicos que leva em conta apenas os custos de fabricação dos objetos considerados em sua materialidade é falsa. A imposição do valor a um bem simbólico passa igualmente pela definição de uma estratégia que vai produzir as condições da eficácia da grife. Bourdieu chama esta estratégia de processo de transubstanciação simbólica que não pode ser resumida a uma transformação material. Estudar este processo abre caminho para uma análise das operações constitutivas da alquimia simbólica. Mais ainda, a imposição da grife produz também uma alquimia social, pois modifica radicalmente a qualidade social (Bourdieu, 2002). 
metodologia) que reduz os intercâmbios sociais a fenômenos de comunicação. Seguindo Bourdieu (1980 e 1986) nesta construção acerca do capital social, busca-se reconhecer o papel fundamental do capital econômico nas relações sociais, sem negligenciar suas formas de inserção cultural, política e simbólica.

Partindo desse conjunto de pressupostos teóricos acerca das relações entre capital social e desenvolvimento local, concebeu-se uma estratégia metodológica que foi experimentada no município de Pintadas, na Bahia ${ }^{10}$. A proposta fundamentou-se em três níveis de análise, a saber:

(a) Visão global do território: histórico do município e das estratégias de desenvolvimento local, visando a enfatizar, a partir de dados secundários (quantitativos e qualitativos), as tendências gerais, os marcos históricos, as rupturas políticas, as lutas sociais e as orientações da coletividade quanto às estratégias implementadas.

(b) Análise das redes sociais: a estrutura das organizações locais de cooperação, incluindo as associações, os sindicatos, as cooperativas, a mídia local, o poder público local. Foi realizada uma análise das organizações à luz de seu perfil administrativo e político, das ações coletivas desenvolvidas, bem como do grau de interação com outros atores locais.

(c) Análise do nível individual de integração social: os questionários individuais (para um total de 406 respondentes) analisaram as questões relacionadas aos valores individuais e co-

10 O município de Pintadas foi escolhido pelo caráter excepcional de suas experiências de desenvolvimento local (Milani, 2006). Ademais, para fins de pesquisa lá foi encontrada a possibilidade de se fazer uma análise das relações sociais com o apoio dos atores do desenvolvimento local, facilitando acesso a documentos, a realização de entrevistas com lideranças e com a população. Situado a $250 \mathrm{~km}$ da cidade de Salvador, a população total do município de Pintadas é de 10927 habitantes (dados de 2000), dos quais 4076 estão na zona urbana e 6851 são moradores da zona rural. A partir desses dados, realizamos 406 entrevistas de forma aleatória - 161 na zona urbana e 245 na zona rural - respeitando o cumprimento do limite mínimo da amostragem (386 pessoas de famílias distintas) da população para um nível de confiança de 95\% (erro amostral de 5\%). 
Capital social e desenvolvimento local: nem cola, nem lubrificante social, mas campo eletromagnético - Carlos R. S. Milani

letivos, à sociabilidade, ao acesso à informação, à confiança nas instituições políticas, às práticas de associativismo e à participação política dos cidadãos.

Muito brevemente, tendo sido concluída a pesquisa, alguns dos resultados são apresentados a seguir. O perfil do pintadense (vide quadro 2) é composto de pessoas com baixa escolaridade, pouca mobilidade (saem pouco de Pintadas), com cerca de $40 \%$ do total de pessoas que lêem jornal ou revista. Os meios de comunicação mais utilizados são o rádio e a TV. No que diz respeito às instituições, a pesquisa revelou que se fala muito de política em Pintadas (para 56,2\% dos entrevistados). Os habitantes de Pintadas consideram que a Prefeitura tem papel central $(63,5 \%)$ no combate às desigualdades. Além disso, 9,9\% dos entrevistados são filiados a um partido político (mais da metade destes $9,9 \%$ no PT). A avaliação da Prefeitura é muito positiva, mas a confiança na Prefeita (para os períodos 1997-2000 e 2001-2004) é superior à confiança na Prefeitura. A confiança na Igreja $(80 \%)$ é bastante elevada, como revela o quadro 3.

\begin{tabular}{|l|c|c|c|c|c|}
\hline Quadro 2 - ACESSO A INFORMAÇÃO E COMUNICAÇÃO \\
\hline $\begin{array}{l}\text { • Você lê jornal ou } \\
\text { revista? }\end{array}$ & $\mathrm{n}$ & $\%$ & $\begin{array}{l}\bullet \text { O que você lê? Jornal ou } \\
\text { revista? }\end{array}$ & $\mathrm{n}$ & $\%$ \\
\hline Sim & 166 & 40,9 & Jornal & 76 & 39,3 \\
\hline Não & 136 & 33,5 & Revista & 117 & 60,7 \\
\hline $\begin{array}{l}\text { Nenhuma das } \\
\text { alternativas }\end{array}$ & 104 & 25,6 & TOTAL & 193 & 100,0 \\
\hline TOTAL & 406 & 100,0 & & & $\%$ \\
\hline $\begin{array}{l}\bullet \text { Com que freqüência } \\
\text { você lê? }\end{array}$ & $\mathrm{n}$ & $\%$ & $\bullet$ Com que freqüência você \\
\hline Todos os dias & 08 & 4,8 & Todos os dias & $\%$ \\
\hline $\begin{array}{l}\text { Algumas vezes por } \\
\text { semana }\end{array}$ & 34 & 20,4 & Algumas vezes por semana & 138 & 34,0 \\
\hline Uma vez por semana & 33 & 19,8 & Uma vez por semana & 29 & 7,1 \\
\hline Uma vez por mês & 92 & 55,0 & Uma vez por mês & 14 & 3,4 \\
\hline TOTAL & 167 & 100,0 & Nunca & 44 & 10,8 \\
\hline & & & TOTAL & 406 & 100,0 \\
\hline
\end{tabular}

Fonte: Pesquisa "Capital Social, Participação Política e Desenvolvimento Local: Atores da Sociedade Civil e Políticas de Desenvolvimento Local na Bahia". 


\begin{tabular}{|c|c|c|c|c|c|}
\hline $\begin{array}{l}\text { Quadro 3-CONFIAN } \\
\text { E NA IGREJA }\end{array}$ & & C & VEK & & \\
\hline $\begin{array}{l}\text { - Fala-se de política na } \\
\text { sua família? }\end{array}$ & $\mathrm{n}$ & $\%$ & $\begin{array}{l}\text { - Qual dos grupos abaixo } \\
\text { tem, na sua opinião, a } \\
\text { obrigação principal no } \\
\text { combate à desigualdade } \\
\text { social em pintadas? }\end{array}$ & $\mathrm{n}$ & $\%$ \\
\hline $\begin{array}{l}\text { Sim, muito } \\
\text { frequentemente }\end{array}$ & 62 & 15,3 & O Governo Federal & 46 & 11,4 \\
\hline Sim, de vez em quando & 166 & 40,8 & O Governo Estadual & 44 & 10,8 \\
\hline Não, raramente & 75 & 18,5 & A Prefeitura & 258 & 63,5 \\
\hline Não, jamais & 103 & 25,4 & As associações & 03 & 0,7 \\
\hline TOTAL & 406 & 100,0 & $\begin{array}{l}\text { As famílias e os parentes das } \\
\text { pessoas pobres }\end{array}$ & 02 & 0,5 \\
\hline & & & Os próprios pobres & 03 & 0,7 \\
\hline & & & Não sabe & 12 & 3,0 \\
\hline & & & Outros & 38 & 9,4 \\
\hline & & & TOTAL & 406 & 100,0 \\
\hline TOTAL & 406 & 100,0 & TOTAL & 406 & 100,0 \\
\hline $\begin{array}{l}\text { - Você tem confiança no } \\
\text { governo federal? }\end{array}$ & $\mathrm{n}$ & $\%$ & $\begin{array}{l}\text { - Você tem confiança na } \\
\text { igreja católica? }\end{array}$ & $\mathrm{n}$ & $\%$ \\
\hline Confio muito & 140 & 34,5 & Confio muito & 325 & 80,0 \\
\hline Confio um pouco & 175 & 43,1 & Confio um pouco & 54 & 13,4 \\
\hline Desconfio & 73 & 18,0 & Desconfio & 26 & 6,4 \\
\hline Não sabe & 18 & 4,4 & Não sabe & 01 & 0,2 \\
\hline TOTAL & 406 & 100,0 & TOTAL & 406 & 100,0 \\
\hline
\end{tabular}

Fonte: Pesquisa "Capital Social, Participação Política e Desenvolvimento Local: Atores da Sociedade Civil e Políticas de Desenvolvimento Local na Bahia".

\begin{tabular}{|l|c|c|c|c|c|}
\hline Quadro 4 - ASSOCIATIVISMO E PARTICIPAÇÃO POLÍTICA & & \\
\hline $\begin{array}{l}\text { - Você participou de } \\
\text { alguma mobilização com } \\
\text { um grupo de pessoas ou } \\
\text { de alguma ação coletiva } \\
\text { nos últimos 12 meses? }\end{array}$ & $\mathrm{n}$ & $\%$ & $\begin{array}{l}\bullet \text { Com que freqüência, } \\
\text { nos últimos doze meses, } \\
\text { você participou de uma } \\
\text { assembléia ou de uma } \\
\text { reunião pública? }\end{array}$ & $\mathrm{n}$ & $\%$ \\
\hline Sim & 120 & 29,6 & Nenhuma & 163 & 40,2 \\
\hline Não & 286 & 70,4 & Uma vez & 46 & 11,3 \\
\hline TOTAL & 406 & 100,0 & Duas vezes & 52 & 12,8 \\
\hline & & & Três ou mais vezes & 145 & 35,7 \\
\hline & & $\%$ & 406 & 100,0 \\
\hline $\begin{array}{l}\text { TOTAL } \\
\text { nos últimos doze meses faz parte de alguma } \\
\text { você procurou um líder } \\
\text { comunitário? }\end{array}$ & associação, cooperativa ou \\
sindicato? & $\mathrm{n}$ & $\%$ \\
\hline Nenhuma & 325 & 80,1 & Sim & 188 & 46,3 \\
\hline
\end{tabular}


Capital social e desenvolvimento local: nem cola, nem lubrificante social, mas campo eletromagnético - Carlos R. S. Milani

\begin{tabular}{|l|c|c|l|c|c|}
\hline Uma vez & 21 & 5,2 & Não & 218 & 53,7 \\
\hline Duas vezes & 18 & 4,4 & TOTAL & 406 & 100,0 \\
\hline Três ou mais vezes & 42 & 10,3 & & & \\
\hline TOTAL & 406 & 100,0 & & & \\
\hline TOTAL & 187 & 100,0 & & & \\
\hline
\end{tabular}

Fonte: Pesquisa "Capital Social, Participação Política e Desenvolvimento Local: Atores da Sociedade Civil e Políticas de Desenvolvimento Local na Bahia".

Quanto aos valores e as normas sociais constitutivos do capital social em Pintadas, percebe-se que há uma estreita relação entre fé cristã e transformação social. As representações sociais de cidadania e compromisso cívico envolvem sistematicamente algum tipo de relação com a Igreja Católica. Vários interlocutores em entrevistas realizadas afirmam que a Igreja é a parceira principal da disseminação das práticas de transformação social em Pintadas. Por intermédio dos apelos à solidariedade e à cooperação, a Igreja estimula a construção do sentido do comunitário e do coletivo: são ilustrações dessa prática os projetos sócio-econômicos implicando a utilização e a gestão de equipamentos comunitários e o trabalho coletivo e associativo praticado no âmbito local. O projeto econômico comunitário é, assim, visto como um meio para organizar os pequenos produtores, oferecendo-lhes possibilidades de ampliar sua participação na sociedade maior, tentando estimular-lhes o senso crítico e a consciência sobre a liberdade, a responsabilidade e os direitos dos cidadãos. A cultura do trabalho coletivo é associada à atuação missionária da Igreja e de sua confiabilidade junto à população.

Além disso, na concepção patrimonial do capital social, há que se levar em conta, no caso de Pintadas, que a identidade coletiva se encontra estreitamente relacionada com o movimento social e as lutas populares. A prática do mutirão e a busca quotidiana por melhoria na qualidade de vida marcam essa identidade. O compromisso público tem origem, entre outros fatores, na luta histórica pela sobrevivência e no combate contra as desigualdades no acesso a terra e água. Pode-se dizer, além disso, que 
a contestação é um elemento-chave para entender a identidade coletiva e o papel da liderança política em Pintadas. Os valores de solidariedade e confiança mútua são destacados pelos líderes do movimento social, mas também pelos habitantes de Pintadas em geral. Como mostram alguns dados da pesquisa (gráfico 1), a solidariedade tem prioridade na escala de valores dos habitantes (seguida pela fraternidade), em detrimento da liberdade e do individualismo.

\section{Gráfico 1}

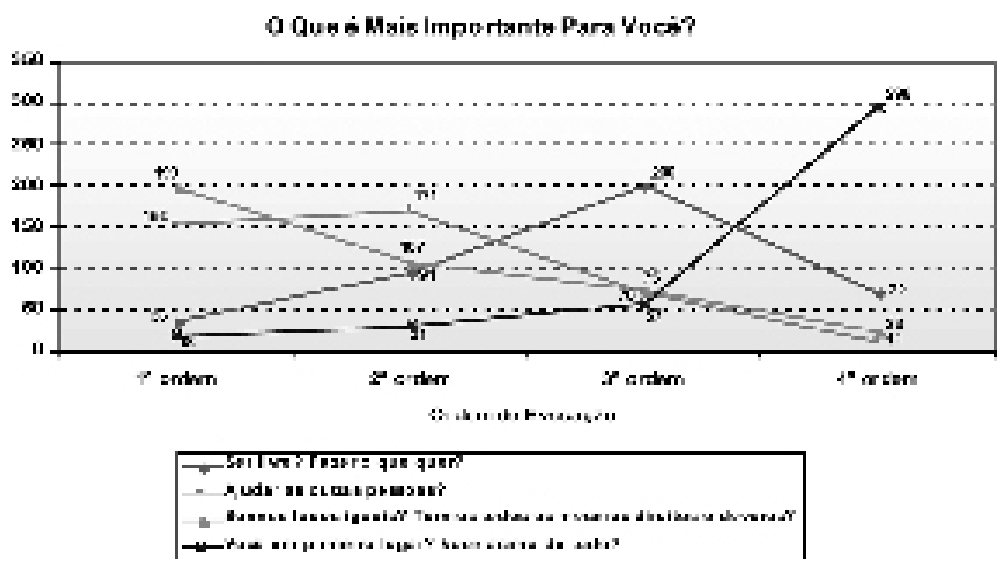

Os valores de solidariedade encontram-se igualmente associados a práticas de participação dos cidadãos na formulação de estratégias de desenvolvimento local (Milani, 2006). Em Pintadas, estimula-se a participação popular por meio de consultas e avaliações freqüentes: na área da saúde, por exemplo, no ano de 2000, quase mil pessoas adultas (para uma população total de cerca de doze mil habitantes) participaram dos diversos encontros preparatórios da Primeira Conferência Municipal de Saúde. Tal participação no campo da saúde pode ser considerada resultado do trabalho anterior realizado pelo Movimento das Mulheres: antes de 1996, o Movimento já exigia do poder público local ações que minimizassem os altos índices de mortalidade em função de câncer de útero e de mama. Junto às comunidades rurais, o Movimento realizou encontros para a discussão sobre a 
Capital social e desenvolvimento local: nem cola, nem lubrificante social, mas campo eletromagnético - Carlos R. S. Milani

saúde durante a campanha eleitoral de 1996, o que resultou no plano de ação municipal na área de saúde. Cinco anos depois, em 2001, o exame preventivo do câncer de útero já era acessível para $98 \%$ das mulheres, tanto da sede quanto da zona rural.

A ação do Congresso Popular (CP) em junho de 2002, outro espaço de forte convergência da população pintadense, também merece destaque. O objetivo principal do $\mathrm{CP}$ foi avaliar, integrar e harmonizar estrategicamente as políticas e ações públicas, estatais e de auto-gestão. Visou também à intensificação da participação popular nas avaliações e decisões e no controle social sobre as práticas públicas locais. Na preparação do $\mathrm{CP}$, foram organizadas reuniões conjuntas com os gestores e lideranças comunitárias, reuniões setoriais e temáticas, bem como doze grandes assembléias populares (duas na sede e dez na zona rural). O CP reuniu, durante dois dias, um total de 267 delegados. Além disso, a plenária deliberativa do $\mathrm{CP}$ contou com a presença de um delegado para cada 30 habitantes acima de 15 anos, com um mandato de dois anos. Suas funções principais foram o acompanhamento dos encaminhamentos definidos pelo Congresso e a mobilização das comunidades e discussão em torno das deliberações. Houve, em 2002, a participação direta no processo do CP (nas reuniões dos gestores e dirigentes, reuniões setoriais e assembléias populares) de mais de 1500 pessoas, ou seja, o equivalente a aproximadamente um quarto da população de Pintadas com mais de 15 anos.

A dinâmica organizacional das redes de cooperação em Pintadas pode ser vista como o resultado de um longo processo histórico iniciado já nos anos 1960. Desde então, o movimento popular em torno dos pequenos produtores rurais de Pintadas tem mobilizado seus recursos e repertórios políticos em parceria direta com os setores mais progressistas da Igreja Católica. As comunidades eclesiais de base incentivaram a formação do Conselho pastoral das comunidades e do Conselho pastoral de jovens. A presença da Pastoral da Terra, a partir da década de 
1980, também fortaleceu as práticas solidárias entre os trabalhadores rurais em torno dos mutirões a serviço principalmente da população rural pintadense (que representa quase dois terços do total da população). A cooperação com agentes da cooperação internacional é outro elemento característico da participação política em Pintadas ${ }^{11}$.

É natural que haja, ainda, inúmeros desafios em termos de desenvolvimento local em Pintadas. No campo de força eletromagnética que representa o capital social em Pintadas, há evidentemente muitas energias latentes e a conversão de capital social em benefícios econômicos não se dá de forma a-histórica, automática e ininterrupta. A dificuldade orçamentária do Município ainda é considerável: Pintadas é um dos municípios baianos com menor arrecadação tributária. Confronta-se, além disso, com o problema da modernização das estruturas agrárias, da disponibilidade de água potável e do isolamento em relação ao mercado (acesso rodoviário difícil e distância dos eixos de circulação da região do semi-árido). É bem verdade que, desde 2004, mais de 95\% dos domicílios rurais já possuem uma cisterna individual para fins de captação da chuva, quebrando a dependência das famílias rurais em relação ao caminhão-pipa no fornecimento de água e, por via de conseqüência, rompendo com a tradição clientelista na gestão de recursos hídricos do semi-árido nordestino. No entanto, com a eleição sucessiva de prefeitos do PT ao governo local desde 1996, Pintadas tem enfrentado dificuldades na relação com o governo estadual no que tange a investimentos em infra-estruturas sócioeconômicas. Por exemplo, coincidência ou não, algumas semanas após o início do mandato da então Prefeita Neusa Cadore

11 O Projeto TAPI - Projeto de Tecnologia Apropriada em Pequena Irrigação - é lançado em 1988, a partir de parceria com o governo francês, visando sobretudo à melhoria da gestão dos recursos hídricos. Dois anos depois, uma agência holandesa cria vínculos com a cidade para a formação de monitores locais, a fim de suprir a ausência de mãode-obra escolarizada. Atualmente, as ONGs internacionais mais presentes em Pintadas são a DISOP (ONG belga: micro-finança), Peuples Solidaires (França, que presta apoio, essencialmente, em matéria de recursos hídricos), Il Canale (Itália: projetos na área de formação) e o DED (Serviço Alemão de Cooperação Técnica e Social: enviando cooperantes para o monitoramento de atividades sócio-produtivas). 
Capital social e desenvolvimento local: nem cola, nem lubrificante social, mas campo eletromagnético - Carlos R. S. Milani

em 1997, a única agência bancária do Município (do Banco do Estado da Bahia) foi fechada, donde a necessidade de criação de uma cooperativa de crédito pelos próprios trabalhadores rurais e membros da rede associativa local. Há esperanças de mudança também em função do câmbio político-institucional a partir dos resultados das eleições de 2006.

\section{Referências bibliográficas}

Atria, Raúl. (2003). “Capital social: concepto, dimensiones y estrategias para su desarrollo". In Atria, Raúl et alii. Capital social y reducción de la pobreza en América Latina y el Caribe: en busca de un nuevo paradigma. CEPAL, Michigan State University, pp. 581-590.

Austruy, Jacques (1992). La chenille et le papillon, économie des métamorphoses. Paris: Editions Cujas.

Baquero, Marcello (2002). "Democracia, cultura e comportamento político: um análise da situação brasileira". In Perissinotto, Renato e Fuks, Mario (orgs.), Democracia, Teoria e Prática. Rio de Janeiro: Relume Dumará, Curitiba: Fundação Araucária, 2002, pp. 105-138.

Becker, Dinizar (2002). "A Economia Política do (Des)envolvimento Regional Contemporâneo". In: Redes (Santa Cruz do Sul), vol. 7, n. 3, pp. 35-59, set/dez 2.

Bourdieu, Pierre (1980). "Le capital social: notes provisoires". In: Actes de la recherche en sciences sociales, volume 31, pp. 2-3.

(1986). "The Forms of Capital". In RICHARDSON, John G. (org.), Handbook of Theory and Research for the Sociology of Education. New York: Greenwood Press, 377 p.

(2002). A Produção da Crença : contribuição para uma economia dos bens simbólicos. São Paulo: Zouk.

Coleman, James (1990). Foundations of Social Theory. Cambridge, Massachusetz, Harvard University Press.

Comparato, Fábio Konder (2001). "Saber combinar o específico e o universal”. In: Lua Nova, número 54, pp. 97-101.

Coutinho, Carlos Nelson (2001). "O desafio dos que pensaram bem o Brasil". In: Lua Nova, número 54, pp. 103-113.

Durston, John (2003). "Capital social: parte del problema, parte de la solución, su papel en la persitencia y en la superación de la pobreza 
en América Latina y el Caribe". In Atria, Raúl et alii. Capital social y reducción de la pobreza en América Latina y el Caribe: en busca de un nuevo paradigma. CEPAL, Michigan State University, pp. 147-202.

Fine, Ben (2001). Social Capital versus Social Theory, Political Economy and Social Science at the Turn of the Millenium. Londres: Routledge, 293 p.

Granovetter, Mark (1973). “The Strength of Weak Ties”. In: American Journal of Sociology, volume 78, número 6, pp. 1360-1380.

(1984). "Economic Action and Social Structure: The Problem of Embeddedness". In: American Journal of Sociology, volume 91, número 2, pp. 481-510.

Hanifan, Lyda (2003). "Social Capital - Its Development and Use". In Ostrom, Elinor e Ahn, T. K. Foundations of Social Capital. Cheltenham (UK), Elgar Reference Collection, pp. 22-35.

Jacobs, Jane (1961). The Death and Life of Great American Cities. New York, Random House.

Lin, Nan (1995). "Les ressources sociales: une théorie du capital social". In: Revue française de sociologie, volume 36, n. 4, pp. 685-704.

Locke, Richard (2001). "Construindo Confiança". In: Econômica, vol. 3, n 2, pp. 253-281.

Meda, Dominique (2002). "Le capital social: un point de vue critique". In: L'Economie Politique, Paris, n. 14, abril de 2002, pp. 36-45.

Milani, Carlos R. S. (2004). “Como articular o 'capital' e o 'social'? Teorias sobre o capital social e implicações para o desenvolvimento local”. In: Redes, UNISC (Santa Cruz do Sul), v. 9, n. 2, p. 31-54.

(2006). "Governo local e cidadania: análise sobre a participação política na Bahia contemporânea". In: ANAIS do III Congresso da Associação Latino-americana de Ciência Política (ALACIP), Campinas, 2006, $26 \mathrm{p}$.

Morgan, Gareth (1996). Imagens da Organização. São Paulo: Atlas.

Morin, Edgar e Kern, Anne Brigitte (1995). Terra-Pátria. Porto Alegre: Sulina, p. 35.

Ostrom, Elinor e Ahn, T. K (2003). Foundations of Social Capital. Cheltenham (UK), Elgar Reference Collection, 590 p.

Putnam, Robert (1993). Comunidade e Democracia: a experiência da Itália moderna. Rio de Janeiro: FGV editora. 
Capital social e desenvolvimento local: nem cola, nem lubrificante social, mas campo eletromagnético - Carlos R. S. Milani

(1995). "Bowling Alone: America's Declining Social Capital". In: Journal of Democracy, janeiro, volume 6, n 1, pp. 65-78.

Reis, Bruno P. W. (2003). “Capital social e confiança: questões de teoria e método". In: Revista de Sociologia e Política, Curitiba, número 21, p. 35-49, nov. 2003.

Robinson, David (2002). "Introduction". In: ROBINSON, David (org.). Building Social Capital. Wellington (Nova Zelândia): Institute for Policy Studies (Victoria University of Wellington), pp. 1-13.

e Robinson, David (2002). "Possible Aids from Physics and Engineering to Assist Understanding Social Capital". In Robinson, David (org.). Building Social Capital. Wellington (Nova Zelândia): Institute for Policy Studies (Victoria University of Wellington), pp. 41-66.

Sciarrone, Rocco (2000). "Réseaux mafieux et capital social". In: Politix, $\mathrm{n}^{\circ}$ 49, Revue des Sciences Sociales du Politique, Publications Hermès Science, pp. 35-36.

Woolcock, Michael (1998). "Social Capital and Economic Development: Toward a Theoretical Synthesis and Policy Framework". In: Theory and Society, 27 (2), pp. 151-208. 